\title{
Monitoring Serum Free Glycoside Concentration in Elderly Patients Receiving Beta-Methyldigoxin
}

\author{
Takatsugu YAMAMOTO*1 Kikuo TAKANO*2 Masaki SANAKA*1,3 \\ Yasushi KUYAMA*3 $^{* 3}$ Mami YAMANAKA*3 Yuichi KOIKE*1 \\ and Satoru MINESHITA*1
}

(Received on April 28, 1997)

*1 Department of Preventive Medicine, Division of Social Medicine, Medical Research Institute,
Tokyo Medical and Dental University
1-5-45 Yushima, Bunkyo-ku, Tokyo 113, Japan
*2 Department of Geriatrics, Sohsen Hospital
*3 Department of Internal Medicine, Teikyo University School of Medicine

The presence of endogenous digoxin-like immunoreactive substance (DLIS) has been reported in several clinical conditions. Because DLIS is absent in protein-free ultrafiltrates of sera, the monitoring of the serum free glycoside concentrations (f-SGC) rather than the total glycoside concentrations (t-SGC) seems more appropriate. We conducted the present study to obtain basic information about monitoring $\mathrm{f}-\mathrm{SGC}$ in patients receiving beta-methyldigoxin (BMD), using TDx digoxin assay.

The results showed that accuracy of the f-SGC detected with TDx assay is almost equal to t-SGC. Additionally, although the BMD-digoxin ratio has some influence on the evaluation of $\mathrm{f}-\mathrm{SGC}$, the impact seemed negligible if individual variance in the albumin concentration is taken into account. These findings suggest that the monitoring of f-SGC rather than t-SGC, is satisfactorily applicable in clinical situations.

Key words : digoxin-like immunoreactive substance, free glycoside concentration, digoxin/beta-methyldigoxin ratio, albumin concentration

\section{Introduction}

Beta-methyldigoxin (BMD), a widely used derivative of digoxin, offers advantages of rapid-onset action and good-absorption ${ }^{1 \sim 5)}$. BMD has the following pharmacological characteristics. 1) Some of BMD molecules absorbed via the intestinal tract undergo

*1 東京医科歯科大学難治疾患研究所社会医学研究 部門予防医学

₹ 113 東京都文京区湯島 1-5-45

*2 総泉病院 $* 3$ 帝京大学医学部内科 demethylation by the liver, and are transformed to some metabolites, including digoxin ${ }^{6,7)}$. Because the serum concentrations of metabolites other than digoxin are below the detection limits of digoxin assays, the serum glycoside concentration (SGC) in a patient receiving $\mathrm{BMD}$ is regarded as a sum of the concentrations of BMD and digoxin. 2 ) Crossreactivity of $\mathrm{BMD}$ against digoxin antibodies is close to $100 \%$, although it varies somewhat among assays ${ }^{8,9)} .3$ ) The positive inotropic and cardiotoxic effects of BMD seem nearly similar 
to those of digoxin ${ }^{10,11)}$. On the basis of those characteristics, therapeutic monitoring in patients receiving BMD can be performed using available digoxin assays, such as fluorescence polarization immunoassay. Regarding the digoxin assays, the possible interference of endogenous digoxin-like immunoreactive substance (DLIS) has been reported in recent years $^{12 \sim 18)}$. Because all digoxin assays are affected by this interference, a new monitoring method not affected by DLIS is now required.

DLIS is absent in protein-free ultrafiltrates of sera, due to its strong proteinbinding ${ }^{19 \sim 21)}$. Based on this finding, a method for monitoring glycoside concentrations in protein-free sera (f-SGC) in patients receiving digoxin was proposed by Dasgupta et al. ${ }^{22)}$, as a substitute for the typical total SGC (t-SGC) measurement. However, to our knowledge, there are no investigations concerning the $\mathrm{f}-\mathrm{SGC}$ in patients receiving BMD. Therefore, we conducted this study to propose basic information which makes the f-SGC usable as a therapeutic tool in patients treated with BMD, using TDx digoxin assay (Dinabot, Tokyo, Japan) which is based on FPIA. Because the serum albumin concentration (Alb) has been known to be a factor which influences the results of the f-SGC, this relationship was examined ${ }^{22}$. Additionally, the impact of the BMD-digoxin ratio in the serum on the evaluation of the f-SGC was also discussed, because of the co-existence of digoxin with BMD in the serum.

The present results showed that accuracy of the measurement of the f-SGC with TDx assay is almost equal to that of the t-SGC. Additionally, although the BMD-digoxin ratio has some influence on evaluating the f-SGC, the impact seemed negligible if individual variance in Alb is taken into account. These findings suggest that the monitoring of the f-SGC, rather than of
t-SGC, is satisfactorily applicable in clinical situations.

\section{Materials and Methods}

The present study comprises two parts. First, as a preliminary experiment, f-SGC, t-SGC, and Alb were measured in standard solutions, to determine the relationships. Next, f-SGCs were measured in patients receiving $\mathrm{BMD}$, and the expected true t-SGCs were obtained by equations derived from the preliminary experiments. The serum used for producing the standard solutions of BMD was obtained from a healthy volunteer who had never received any glycosides. Written informed consent was obtained from the volunteer before blood sampling. From all the patients participating in this study or their family members, consent was orally obtained. This protocol was approved by the local ethical committee.

\section{Preliminary Experiments}

Six levels of digoxin standard sera and five of BMD solutions were prepared for examining the accuracy of the measurement of the f-SGC. Digoxin sera $(0.5,0.75,1.0,1.5,2.0$ and $3.5 \mathrm{ng})$ were purchased from Dinabot Co. (Tokyo, Japan), while the standard sera of BMD were made as follows. A tablet of BMD (Lanirapid, Yamanouchi, Tokyo, Japan) was powdered and dissolved in distilled water containing $40 \mathrm{mg}$ of ethanol and $200 \mathrm{mg}$ of propylene glycol per $1 \mathrm{ml}$. The BMD solution was divided and contaminated with the serum of a healthy volunteer at various rates, to obtain concentrations of $0.5,1.0,2.0,4.0$ and $5.5 \mathrm{ng} / \mathrm{ml}$. After incubation at $37^{\circ} \mathrm{C}$ for $3 \mathrm{hrs}$., the solutions were left at room temp. for $30 \mathrm{~min}$., then used for the tests.

Each standard sera was divided into three parts to detect the following concentrations : 
a. Digoxin

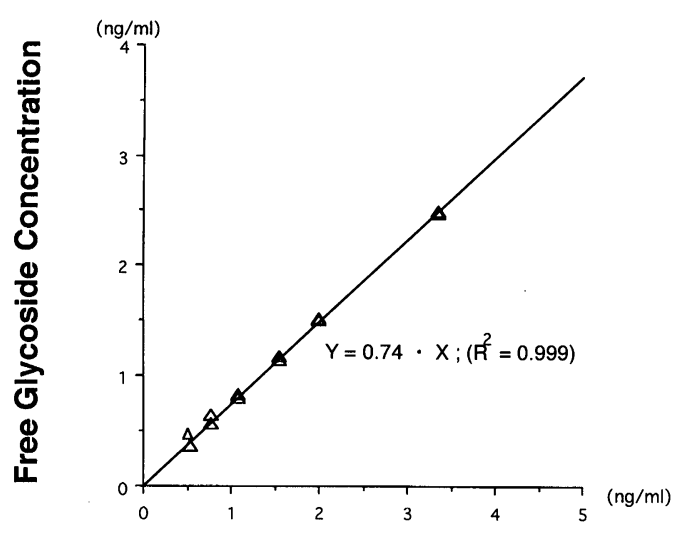

b. $\beta$-methyldigoxin

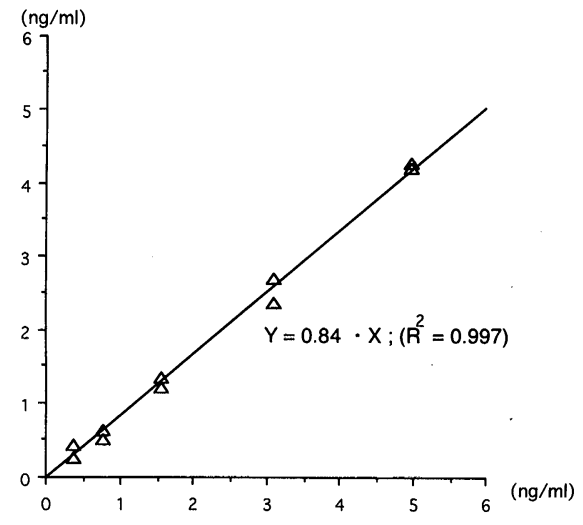

\section{Total Glycoside Concentration}

Fig. 1 Relationship between total and free serum glycoside concentration in the digoxin (a) and $\beta$-methyldigoxin (b) control sera. The free glycoside concentration is closely correlated with the total glycoside concentrations in the control sera. The albumin concentrations of the sera ranged from 4.3 to $4.8 \mathrm{~g} / \mathrm{dl}$.

t-SGC, f-SGC, and Alb. The protein-free serum was obtained by ultrafiltration with a micropartition device (MPS-3, AMICON, U.S. A.), at $1,500 \mathrm{~g}$ for $20 \mathrm{~min}^{19,20)}$. The SGCs were measured as described in the manufacturer's guideline. Coefficients of variation (CV) within assay $(n=5)$ and that between assays $(n=5)$ in the measurement of the f-SGC were also determined using digoxin standard serum $(0.75 \mathrm{ng} /$ $\mathrm{ml}$ ). Alb was detected by dye method.

In the next step for clarifying the relationship between Alb and the $\mathrm{f}-\mathrm{SGC} / \mathrm{t}$-SGC ratio, other $\mathrm{BMD}$ and digoxin solutions were made with different Alb. The t-SGC, the f-SGC and Alb in those samples were measured in the same way as described above, and the relationship between $\mathrm{Alb}$ and the $\mathrm{f}-\mathrm{SGC} / \mathrm{t}-\mathrm{SGC}$ ratio was determined.

\section{Patient Study}

Eighty-eight patients (Sohsen Hospital, Chiba, Japan) who received BMD and under- went periodical measurement of the t-SGC were selected as participants. They underwent glycoside therapy because of congestive heart failure (60 patients) or other cardiac disorders (28 patients). Using left-over specimen after required t-SGC measurements, the $\mathrm{f}-\mathrm{SGC}$ and Alb were measured.

\section{Results}

In the preliminary experiments, the CVs within assay and between assays were $5.2 \%$ and $8.5 \%$, respectively, which seemed satisfactorily applicable clinically. When Alb was at a similar level $(4.3 \sim 4.8 \mathrm{~g} / \mathrm{dl})$, the $\mathrm{f}-\mathrm{SGC} / \mathrm{t}$-SGC ratios were quite constant in the control sera, as shown in Figure 1. However, in the cases where Alb varied greatly, the ratios were considerably changed in relation to Alb (Fig. 2). From these results, the following equations (Eq.) were derived:

$$
\mathrm{f} \text {-digoxin/t-digoxin }=0.89-0.035 \cdot \mathrm{Alb}
$$


a. Digoxin

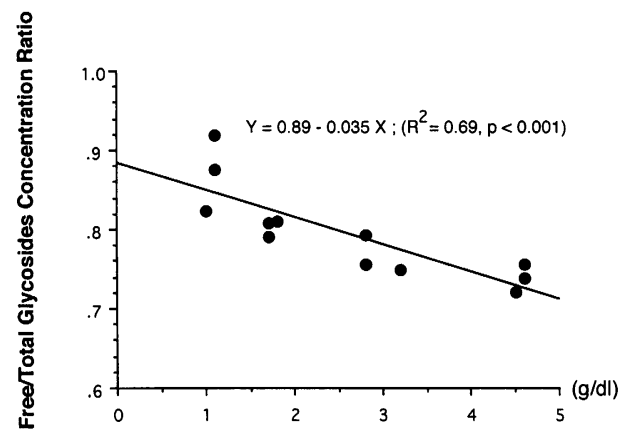

b. $\beta$-methyldigoxin

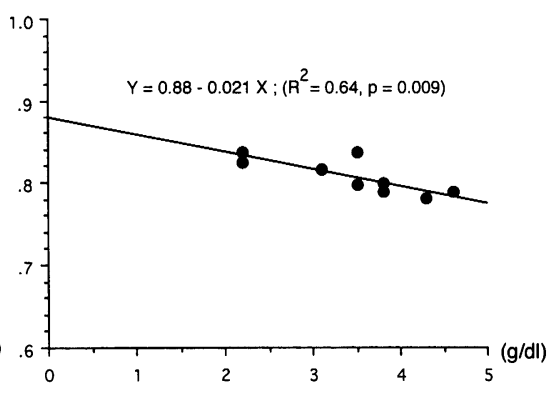

Serum Albumin Concentration

Fig. 2 Relationship between serum albumin concentration and free/total glycoside concentration ratio in the digoxin (a) and $\beta$-methyldigoxin (b) control sera. In both cases, the free/total glycoside concentration ratios show a negative correlation with serum albumin concentration.

$$
\mathrm{f}-\mathrm{BMD} / \mathrm{t}-\mathrm{BMD}=0.88-0.021 \cdot \mathrm{Alb}
$$

where f- or t-digoxin means f- or t-SGC attributed to digoxin segment, and likewise, $\mathrm{f}$ - or $\mathrm{t}$ $\mathrm{BMD}$. Alb is described in $\mathrm{g} / \mathrm{dl}$.

We then, tried to obtain the true t-SGC value and the DLIS concentration from the $\mathrm{f}$-SGC in the patients. The patient characteristics are shown in Table 1. Since the t-SGC in the serum of a $\mathrm{BMD}$ receiver is calculated by addition of the $\mathrm{t}$-digoxin and the $\mathrm{t}-\mathrm{BMD}$, following equation is obtained.

$$
\begin{aligned}
\mathrm{t}-\mathrm{SGC}= & \mathrm{t}-\text { digoxin }+\mathrm{t}-\mathrm{BMD} \\
= & \mathrm{f}-\text { digoxin } /(0.89-0.035 \cdot \mathrm{Alb})+ \\
& \mathrm{f}-\mathrm{BMD} /(0.88-0.021 \cdot \mathrm{Alb})
\end{aligned}
$$

Assuming that the ratio of digoxin concentration per total glycoside concentrations in the protein-free ultrafiltrates is $\alpha(0 \leqq \alpha \leqq 1)$, the Eq. (3) is transformed to the Eq. (4).

$$
\begin{aligned}
\mathrm{t}-\mathrm{SGC}= & \mathrm{f}-\text { digoxin } /(0.89-0.035 \cdot \mathrm{Alb})+ \\
& \mathrm{f}-\mathrm{BMD} /(0.88-0.021 \cdot \mathrm{Alb})
\end{aligned}
$$

$$
\begin{aligned}
= & \alpha \cdot \mathrm{f}-\mathrm{SGC} /(0.89-0.035 \cdot \mathrm{Alb})+ \\
& (1-\alpha) \cdot \mathrm{f}-\mathrm{SGC} /(0.88-0.021 \cdot \mathrm{Alb}) \\
= & \mathrm{f}-\mathrm{SGC} \cdot\{\alpha /(0.89-0.035 \cdot \mathrm{Alb})+ \\
& (1-\alpha) /(0.88-0.021 \cdot \mathrm{Alb})\}
\end{aligned}
$$

where $\alpha=0$ means the case in which BMD is not metabolized at all, and $\alpha=1$ means the case in which BMD is completely metabolized to digoxin. This equation suggests that the value of the calculated t-SGC is affected by Alb and $\alpha$ to some extent. Figure 3 shows the effect on the t-SGC/f-SGC ratio. Using Eq. (4), t-SGC in the patients was calculated by the measured Alb, the measured f-SGC, and a hypothesized value of $\alpha=0.5$. Figure 4 demonstrates the relationship between the measured and the calculated t-SGC. The measured f-SGC was equal to or larger than the calculated t-SGC in most cases, which seems compatible with the fact that the measured f-SGC is calculated by the true t-SGC plus the DLIS concentration. Figure 5 shows the DLIS concentrations obtained by the measured 
Table 1 Patient Characteristics

$(\mathrm{n}=88$, male ; 34 , female ; 54$)$

\begin{tabular}{lc}
\hline \multicolumn{1}{c}{ Characteristics } & Mean (S. D) \\
\hline Age (year) & $81.1(7.1)$ \\
Body weight $(\mathrm{kg})$ & $41.2(8.5)$ \\
Serum albumin $(\mathrm{g} / \mathrm{dl})$ & $3.3(0.5)$ \\
Serum creatinine $(\mathrm{mg} / \mathrm{dl})$ & $1.0(0.6)$ \\
Creatinine clearance $\#(\mathrm{ml} / \mathrm{min})$ & $36.7(18.2)$ \\
Given dose of BMD $(\mathrm{mg})$ & $0.083(0.041)$ \\
\hline
\end{tabular}

$\mathrm{BMD}: \beta$-methyldigoxin

\# : Calculated by Cockcroft-Gault's method

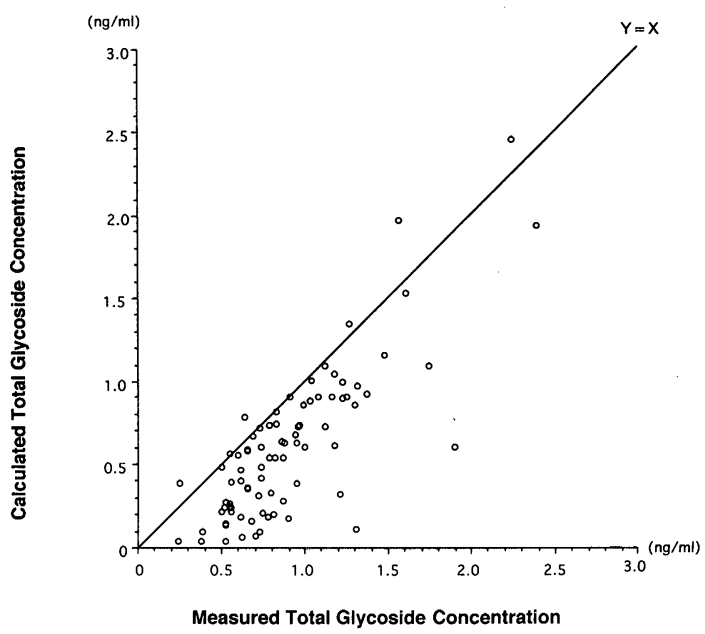

Fig. 4 Relationship between measured and calculated total glycoside concentrations in patients receiving $\beta$-methyldigoxin

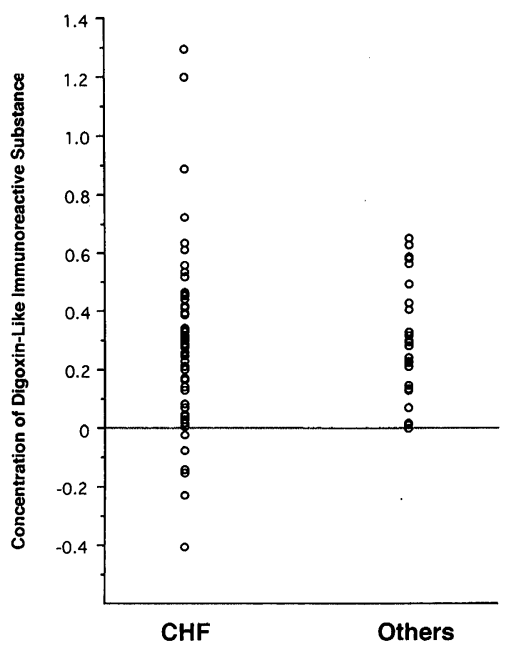

Fig. 5 Concentration of calculated digoxin-like immunoreactive substance in patients receiving $\beta$-methyldigoxin. "CHF" means the patients receiving $\beta$-methyldigoxin due to congestive heart failure $(n=60)$, while "Others" indicates those who receive $\beta$-methyldigoxin because of other heart diseases $(n=28)$. 
t-SGC minus the calculated t-SGC, where $\alpha$ is postulated as 0.5 .

\section{Discussion}

The presence of DLIS is a very troublesome problem for clinicians who treat patients with cardiac glycosides. The false-positive SGCs in patients not having received any cardiac glycosides sometimes reached the therapeutic range, suggesting that a considerable overestimate for a given dosage of cardiac glycosides may be present in clinical cases $^{23 \sim 25)}$. Since DLIS is absent in protein-free sera, the measurement of $\mathrm{f}$-SGC seems preferable to that of the t-SGC. Additionally, f-SGC is a reasonable monitoring tool in terms of the pharmacological principle that actual drug actions depend on the protein-unbound fraction. However, because little information about f-SGC is available, examination of the free-total SGC relationship and calculation of the true t-SGCs from the measured f-SGC are important for entablishing f-SGC monitoring.

Serum albumin concentration is a factor which influences the relationship between $t$ SGC and f-SGC even in cases of BMD, as well as in cases of digoxin ${ }^{21,22)}$. However, Alb is determined easily in routine clinical test, and its impact can be taken into account, as demonstrated in the Eq. (4). Concerning patients receiving $\mathrm{BMD}$, additionally, the co-existence of digoxin with BMD in the serum may possibly affect the free-total SGC relationship, because the $\mathrm{BMD} /$ digoxin ratio greatly varies among individuals due to differences of the two substances in clearance, distribution, proteinbinding rate, or another pharmacokinetic properties $^{1 \sim 7)}$. The BMD/digoxin ratio cannot be determined by TDx digoxin assay alone, so we estimated the impact using a rational calculating method. The results showed that the vari- ances of the calculated t-SGC in the case with the f-SGC of 1.0 and $2.0 \mathrm{ng} / \mathrm{ml}$ are at most 0.08 and $0.16 \mathrm{ng} / \mathrm{ml}$, respectively (Fig. 3). This indicates that the disability of this calculating method for t-SGC is not larger than the detection limit of the assay $(0.2 \mathrm{ng} / \mathrm{ml})$, and the free-total SGC relationsphip can be determined by the f-SGC and Alb.

This method is also useful in calculating the DLIS concentration. Most of the measured tSGCs showed larger values than the calculated t-SGC, strongly indicating the existence of DLIS (Fig. 4). If this finding were largely attributed to the incomplete ability of the calculating method, there should be much more cases in which the calculated t-SGC exceeds the measured $\mathrm{t}$-SGC. Interestingly, the DLIS concentration in patients suffering from congestive heart failure seems higher than that in other patients as shown in Figure 5. This seems consistent with the fact that patients with congestive heart failure are likely to suffer from interference caused by DLIS. However, it remains unclear whether the DLIS concentrations are correct or not because no method for determining DLIS concentration has been established yet.

Therapeutic monitoring of cardiac glycosides should be more accurate and more correlated to clinical effectiveness. From this viewpoint, the monitoring f-SGC rather than t-SGC is encouraged, due to the existence of DLIS. We believe the present results will propose basic rationale for monitoring $\mathrm{f}-\mathrm{SGC}$ in patients with BMD.

\section{References}

1) Rietbrock, N., Abshagen, U., Bergmann, K. U., et al. : Disposition of $\beta$-methyldigoxin in man. Eur. J. Clin. Pharmacol., 9 : 105-114 (1975).

2) Boerner, D., Olcay, A., Schaumann, W., et al. : Absorption of $\beta$-methyl-digoxin determined 
after a single dose and under steady state conditions. Eur. J. Clin. Pharmacol., 9 : 307-314 (1976).

3) Rietbrokc, N., Guggenmos, J., Kuhlmann, J., et al. : Bioavailability and pharmacokinetics of $\beta$ methyldigoxin after multiple oral and intravenous doses. Eur. J. Clin. Pharmacol., 9 : 373379 (1976)

4) Keller, F., Blumenthal, H. P., Maertin, K., et al. : Overall pharmacokinetics during prolonged treatment of healthy volunteers with digoxin and $\beta$-methyldigoxin. Eur. J. Clin. Pharmacol., $12: 387-392$ (1977).

5) Hayward, R. P., Greenwood, H. and Hamer, J. : Comparison of digoxin and medigoxin in normal subjects. Br. J. Clin. Pharmacol., 6 : 81-86 (1978).

6) Hinderling, P. H., Garrett, E. R. and Wester, R. C. : Pharmacokinetics of $\beta$-methyldigoxin in healthy humans II : oral studies and bioavailability. J. Pharm. Sci., 66 : 314-325 (1977).

7) Belz, G. G., Stauch, M., Belz, G., et al.: The effect of various cardenolides and bufadienolides with different cardiac activity on the ${ }^{86}$ rubidium uptake of human erythrocytes. Naunyn Schmiedebergs Arch. Pharmacol., 280 : 353-362 (1973).

8) Nakashima, H., Tsutsumi, K., Hashiguchi, M., et al. : Pharmacokinetics of beta-methyldigoxin. Jpn. J. Clin. Pharmacol. Ther., 20:441-446 (1989) (in Japanese).

9) Tsutsumi, K., Nakashima, H., Kumagai, Y., et al. : TDM of digoxin and $\beta$-methyldigoxin. Jpn. J. Clin. Pharmacol. Ther., 22 : 459-469 (1991) (in Japanese).

10) Shaumann, W. and Koch, K.: $\beta$-methyl-digoxin : VII. Tissue distribution, positive inotropic and central action in cats in comparison with other digitalis glycosides. Naunyn Schmiedebergs Arch. Pharmacol., 286 : 195-210 (1974).

11) Das, G., Talmers, F. N., Smith, W. S., et al. : Comparison of cardiotropic effects and serum glycoside levels to beta-methyldigoxin and digoxin in man. Clin. Pharmacol. Ther., 19: 105 (1976).

12) Graves, S. W., Valdes, R. J., Brown, B. A., et al : Endogenous digoxin-immunoreactive substance in human pregnancies. J. Clin. Endocrinol. Metabol., $58: 748-751$ (1984)

13) Valdes, R. J., Graves, S. W., Brown, B. A., et al. : Endogenous substance in newborn infants causing false positive digoxin measurements. J. Pediatr., 102 : 947-950 (1983).
14) Graves, S. W., Brown, B. A. and Valdes, R. J. : An endogenous digoxin-like substance in patients with renal impairment. Ann. Intern. Med., 99 : 604-608 (1983).

15) Nanji, A. A. and Greenway, D. C. : Falsely raised plasma digoxin concentrations in liver disease. Br. Med. J., 290 : 432-433 (1985).

16) Sagnella, G. A., Markandu, N. D., Buckley, M. G., et al.: Endogenous digoxin-like immunoreactivity in congestive heart failure. Br. Med. J., 295 : 415-416 (1987).

17) Varsano, S., Shilo, L., Bruderman, I., et al. : Endogenous digoxin-like immunoreactive factor is elevated in advanced chronic respiratory failure. Chest, 101 : 146-149 (1992).

18) Clenico, A., Bolzen, S., Del Chicca, M. G., et al. : Endogenous cardiac glycoside-like substances in newborns, adults, pregnant women and patients with hypertension or renal insufficiency. Drug Exp. Clin. Res., 14 : 603-607 (1988).

19) Graves, S. W., Sharma, K. and Chandler, A. B. : Methods for eliminating interferences in digoxin immunoassays caused by digoxin-like factors. Clin. Chem., 32 : 1506-1509 (1986).

20) Christenson, R. H., Studenberg, S. D., Beck-Davis, S., et al. : Digoxin-like immunoreactivity eliminated from serum by centrifugal ultrafiltration before fluorescence polarization immunoassay of digoxin. Clin. Chem., 33:606-608 (1987).

21) Dasgupta, A., Saldana, S. and Heimann, P.: Monitoring free digoxin instead of total digoxin in patients with congestive heart failure and high concentrations of digoxin-like immunoreactive substances. Clin. Chem., 36 : 2121-2123 (1990).

22) Dasgupta, A., Schammel, D. P., Limmany, A. C., et al. : Estimating concentrations of total digoxin and digoxin-like immunoreactive substances in volume-expanded patients being treated with digoxin. Ther. Drug Monit., 18 : 34-39 (1996).

23) Valdes, R. J. : Endogenous digoxin-like immunoreactive factors : impact on digoxin measurements and potential physiological implications. Clin. Chem., 31: 1525-1532 (1985).

24) Yamamoto, T., Takano, K., Sanaka, M., et al. : A false positive serum digoxin level in elderly patients. Jpn. J. Pharmacol. Ther., $27: 481-488$ (1996).

25) Gault, M. H., Vasdev, S. and Longerich, L. : Higher values for digitalis-like factors with $\mathrm{TDx}$ Digoxin II. Clin. Chem., 32:2000-2001 (1986). 